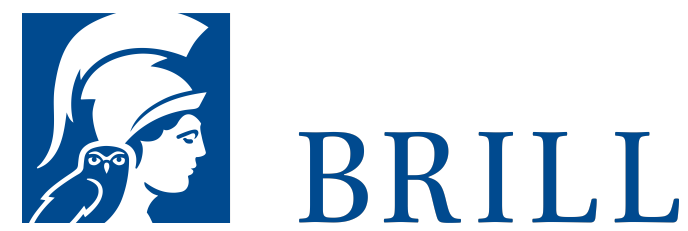

\title{
Unterbestimmtheit und pragmatische Aprioris
}

Vom Tribunal der Erfahrung zum wissenschaftlichen Prozess

Author: Michael Anacker

Die Unterbestimmtheitsthese ist in der

wissenschaftstheoretischen Diskussion wesentlicher

Bestandteil der Realismus-Debatte. Sie thematisiert das

Verhältnis wissenschaftskonstitutiver, theoretischer Aspekte zur Empirie und dessen philosophische Konsequenzen. Die forschungspraktische Bedeutung von Unterbestimmtheiten für die Wissenschaften gerät nie in den Blick. Die vorliegende Untersuchung kommt nach einer philosophiehistorischen Rekonstruktion der Unterbestimmtheitsthese bei Duhem, Neurath und Quine zu dem Ergebnis, dass es keine einheitliche Unterbestimmtheitsthese gibt: Unterbestimmtheit übernimmt bei den drei Autoren je unterschiedliche Rollen, die nur vor dem Hintergrund ihrer philosophischen Gesamtkonzeption angemessen zu verstehen sind, aber keine Rückschlüsse auf eine realistische oder instrumentalistische Interpretation von Wissenschaften erlauben. Dieses Buch schlägt einen anderen Weg zur Analyse von Unterbestimmtheiten ein: Es rekonstruiert ausgehend von William James' und C. I. Lewis' Verständnis der konstitutiven Bedingungen von Wissenschaften theore tische Rahmenbedingungen als pragmatische Aprioris, die dem historischen Wandel unterliegen. Im Zuge dieses Wandels können sich die apriorischen Bedingungen semantisch aufladen und werden der empirischen Erforschung zugänglich. In diesem Prozess werden sie von formalen Bedingungen der Forschungspraxis...

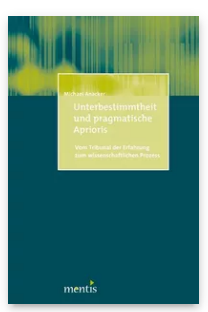

Pages: 240

Seiten

Language:

German

Subjects:

General,

Philosophy

Publisher: Brill | mentis

E-Book (PDF)

Released online:

23 May 2012

ISBN: $978-3-$

89785-948-7

List price

USD \$ \$ 48.00

Paperback

Publication date:

23 May 2012

ISBN: $978-3-$

89785-772-8

List price

USD $\$ 48.00$ 
For more information see brill.com

Order information: Order online at brill.com +44330 333 0049 | customerservices@brill.com Submission information: brill.com/authors

Titles published by Brill | Fink, Brill | mentis or Brill | Schöningh: +49(o)715413279216| brill@brocom.de 